\title{
Similarities in Drinking Behavior of Twin's Friends: Moderation of Heritability of Alcohol Use
}

\author{
Evelien A. P. Poelen · Rutger C. M. E. Engels • \\ Ron H. J. Scholte · Dorret I. Boomsma • \\ Gonneke Willemsen
}

Received: 4 February 2008/ Accepted: 8 December 2008/Published online: 27 December 2008

(C) The Author(s) 2008. This article is published with open access at Springerlink.com

\begin{abstract}
Previous research has indicated that friends' drinking may influence alcohol use in adolescents and young adults. We explored whether similarities in the drinking behavior of friends of twins influence the genetic architecture of alcohol use in adolescence and young adulthood. Survey data from The Netherlands Twin Register were available for 1,526 twin pairs aged 16-25 years. We categorized the twin pairs as concordant (both report similar alcohol use in their friends) or discordant for the alcohol use of their friends. Genetic moderator models were tested by carrying out multi-group analyzes in Mplus. Findings showed a significant moderation effect. Genetic factors were more and common environment less important in the explanation of variation in alcohol use in twins discordant for alcohol use of friends than in twins concordant for alcohol use of friends.
\end{abstract}

Keywords Genetic moderation models .

Alcohol use frequency - Regular alcohol use .

Friends of twins

\section{Introduction}

Twin studies have shown that genes are important in the prediction of individual differences in alcohol use of

Edited by Michael Lyons.

E. A. P. Poelen $(\bowtie) \cdot$ R. C. M. E. Engels · R. H. J. Scholte Behavioural Science Institute, Radboud University Nijmegen, P.O. Box 9104, 6500 HE Nijmegen, The Netherlands e-mail: e.poelen@pwo.ru.nl

D. I. Boomsma · G. Willemsen

Biological Psychology, VU University Amsterdam, Van der Boechorststraat 1, 1081 BT Amsterdam, The Netherlands adolescents who have developed regular drinking patterns (see review by Hopfer et al. 2003). Pagan et al. (2006) and Viken et al. (1999) found in 16-17 year olds that genetic factors explained approximately $40 \%$ of the variance in frequency of drinking, while Fowler et al. (2007a) found that genes played even a larger role in the variance of quantity of drinking in 11-19 year olds, predicting 64\% of the individual differences in alcohol use.

While studies have shown genetic factors to be important, they also point to a role of environmental factors in explaining individual differences in drinking. One of these environmental factors may be the drinking behavior of friends. Several non-twin studies have indicated that friends' drinking is one of the strongest predictors of young people's alcohol use (e.g., Andrews et al. 2002; Ary et al. 1993; Graham et al. 1991; Petraitis et al. 1995; Urberg et al. 1997; Wood et al. 2001), though the extent of the influence may change with the duration of the follow-up (Poelen et al. 2007). The influence of friends is also supported by a twin study of Walden et al. (2004), that pointed to the relevance of friends' behavior (i.e., friends' substance use and friends' delinquency) in explaining adolescents' substance use.

The drinking behavior of friends may also interact with genetic influences. In a study of Dick et al. (2007) in 17 year old Finnish twins, genetic influences on adolescent drinking were higher and common environmental influences were lower among adolescents with a larger number of drinking friends compared to adolescents with a small number of drinking friends. According to the authors these results suggest that environments characterized by high levels of friends' drinking create opportunities for genetic predispositions to be expressed.

If the drinking behavior of friends modifies genetic influences, twin studies taking the drinking behavior of the 
friends of twins into account, would provide a more complete picture of the factors influencing alcohol use in adolescence. When doing so, the extent to which twins share their friends becomes highly relevant. Several twin studies have indicated that in adolescence monozygotic (MZ) twins are more likely than dizygotic (DZ) twins to share all or nearly all of their friends (Horwitz et al. 2003; Rende et al. 2005; Rose 2002; Walden et al. 2004). According to Horwitz et al. (2003), twin studies may overestimate the strength of genetic influences and underestimate the strength of common environmental influences, because higher similarities in behavior among $\mathrm{MZ}$ compared to DZ twins do not only arise through genetic differences but also through social influences (i.e., friends). In other words, when MZ twins are more similar for a trait than DZ twins because they share more aspects of their environments than DZ twins, the actual environmental effect on this trait will be attributed to genetic effects. Rende et al. (2005) examined whether having mutual friendships in twin pairs moderated the genetic and shared environmental estimates of alcohol use in seven through twelve graders in a US sample. Their findings showed that the heritability of alcohol use was not significantly moderated by the extent to which twins shared their friends, but shared environmental effects were stronger in twin pairs with more mutual friends than in twin pairs with few mutual friends.

Both the sharing of friends and the similarities in alcohol use of friends might affect estimates of heritability and common environment. In addition to sharing the same friends, twins can also have different friends who behave similarly. In this respect, research showed that MZ twins were more likely to have similarly behaving friends than DZ twins (Horwitz et al. 2003; Rose 2002). No study so far has tested whether heritability is moderated by the concordance for the alcohol use of their friends.

The main aim of this study was to examine whether concordance (both twins report similar alcohol use in their friends) or discordance for the alcohol use of friends moderates the influence of genetic factors and common environment on alcohol use. We focus on similarity in drinking among the friends of twins and not on drinking behavior itself of friends. If twins have the same friends or behaviorally similar friends, this should be reflected in an increased similarity in the twins' drinking behavior, which may influence estimates of heritability and the influence of the common and unique environment.

\section{Methods}

\section{Participants}

In the current study, we used data of a longitudinal questionnaire study of the Netherlands Twin Register. Every
2-3 years adolescent and young adult twins and their family members are asked to complete a questionnaire on their health, lifestyle and personality. Questionnaires have been sent out in 1991, 1993, 1995, 1997, 2000, 2002 and 2004. Some twins participated only once, while others participated several times. For more detailed information about sample and data collection we refer to Boomsma et al. (2002, 2006).

For the purpose of this study we used data of the 1993 and 1995 data collections, as in these waves twins were asked to indicate to what extent they had their friends in common. All data from twins in the age of 16-25 were selected for analyzes. In The Netherlands it is legal to drink alcohol as of the age of 16 . At this age, people mainly drink in company of their friends and their drinking behavior is more likely to be affected by friends than the behavior of younger Dutch adolescents who drink more often in company of their parents (Van Der Vorst et al. 2007).

We used the data of twin pairs from the 1993 wave of data collection, and complemented that with data from the 1995 wave. In case data for a complete twin pair were not available for 1993, but were available for 1995, we used the data from the 1995 wave. This resulted in a sample of 237 monozygotic male (MZM) twin pairs, 232 dizygotic male (DZM) twin pairs, 357 monozygotic female (MZF) twin pairs, 264 dizygotic female (DZF) twin pairs and 436 dizygotic opposite sex (DOS) twin pairs, all complete twin pairs. The mean age of these twin pairs was 19.4 years $(\mathrm{SD}=2.7)$. Zygosity of the twins was based on DNA polymorphisms, or on survey questions regarding the physical similarity of the twins and confusion in identifying the twins by family members, friends and strangers in case DNA polymorphisms were not available. The agreement between zygosity based on DNA polymorphisms and zygosity based on questionnaires is $97 \%$ (Willemsen et al. 2005).

\section{Measures}

Frequency of drinking in twins was measured with the question: "How often do you drink alcohol?" This question had eight response categories: (1) "I do not drink alcohol", (2) "once a year or less", (3) "a few times a year", (4) "about once a month", (5) "a few times a month", (6) "once a week", (7) "a few times a week", and (8) "daily" (Poelen et al. 2005). Category 8 was not present in all subgroups, therefore categories 7 and 8 were collapsed into one category, creating a 7-point frequency of drinking measure. To be able to compare our results with studies which used dichotomized drinking (e.g., Koopmans and Boomsma 1996), we also transformed the original measure into the dichotomous regular drinking measure, consisting of non-regular drinking and regular drinking, which was 
defined as drinking a few times a month or more (Poelen et al. 2007).

In 1993 and 1995 the questionnaires contained the item: "Do you and your co-twin have the same friends?" The response categories were: (1) "all friends are shared", (2) "some of our friends are mutual", (3) "we both have our own friends", and (4) "I don't have friends". Less than $1 \%$ of the twins indicated that they did not have friends, therefore we excluded the data of these twins from our analyzes.

Twins were also asked how many of their friends drink alcohol on a regular basis. Answer categories were: (1) "no one", (2) "a few", (3) "around half" (4) "most", and (5) "all". Based on the answers to these two questions, we created a new variable consisting of three categories: (1) "all friends in common", (2) "different friends who are similar in alcohol use" and (3) "different friends who differ in alcohol use". Only if both twins indicated to have all friends in common and if they reported similar alcohol use of friends, twins were classified in the first category. We refer to this category as the "concordant". Twins were classified as discordant when they both indicated to have only some of their friends in common, or to have their own friends, and reported differently on the alcohol use of their friends. When one twin reported to have all their friends in common while the other twin reported that they only had part or none of their friends in common twin pairs, and differed in their reports of their friends' alcohol use were also categorized as discordant.

\section{Strategy of analyses}

We first examined whether MZ twins more often had all friends in common and more often had friends with similar alcohol use than DZ twins. Frequency distributions were tested for statistical differences using Chi-square tests in SPSS 15.0. Next, polychoric correlations and genetic models were evaluated in Mplus (Muthén and Muthén 1998-2006). We calculated polychoric correlations for all zygosity groups (MZM, DZM, MZF, DZF and DOS) separately for twin pairs who were concordant for the alcohol use of their friends and twin pairs who were discordant the alcohol use of their friends.

Genetic model fitting was done conditional on concordant/discordant status of the pair. This approach to test for gene-environment (GE) interaction has been described by Eaves (1982); Heath et al. 1998; (see also Heath 1987) and Boomsma et al. (1999). The analyzes involves a multigroup analyzes (five zygosity-by-zygosity groups by concordance/discordance status). The test for GE interaction is carried out by testing whether model parameter estimates (e.g., for heritability) are the same for concordant and discordant twins.
Because the alcohol variables were categorical, the weighted least square estimator with a mean- and varianceadjusted chi-square test statistic (WLSMV) was used. This is default for categorical data (Muthén and Muthén 19982006; Prescott 2004). An underlying liability, or vulnerability for alcohol used was assumed, which is normally distributed with unit variance and zero mean. One or more thresholds divide the liability into two or more categories. Thresholds are estimated based on the observed distribution of scores in the categories (Prescott 2004).

The variance of the liability distribution for frequency of drinking and for regular drinking was modeled as a function of four influences: age, additive genetic effects (A), common environmental effects $(\mathrm{C})$ and unique environmental effects (E). The estimates of unique environmental effects also include measurement error. A, C and $\mathrm{E}$ were standardized to have unit variance. The correlation between the latent $\mathrm{A}$ effects $\left(r_{\mathrm{A}}\right)$ for MZ twins was fixed to 1 , while the correlation between the A factors for DZ twins was fixed to .5. The correlation between the common environmental latent factors $\left(r_{\mathrm{C}}\right)$ was fixed at 1 . Unique environmental (E) latent factors were not correlated by definition (e.g., Boomsma et al. 2002). The effect of age was modeled on the thresholds.

Models were fit directly to the raw data. Frequency of drinking was assessed by seven categories and six thresholds to model this variable. Regular drinking was assessed by two categories, therefore there was one threshold. Because of sex differences in the distribution of regular drinking and frequency of drinking (Poelen et al. 2005, 2007) separate thresholds for male and female twins were estimated. When the WLSMV estimator for categorical data is used, the comparison of different submodels cannot be based on subtracting the chi-squares and degrees of freedom, because the difference in chi-square values for two nested models is not distributed as chi-square. We therefore used the special option in Mplus for difference testing when the WLSMV estimator is used; as described in detail in the Mplus User's Guide (Muthén and Muthén 1998-2006).

We first fitted the complete model in same-sex twin pairs and tested whether the effects of age and A, C, and E factors differed for males and females. We carried out a multi-group analysis with eight groups (zygosity by sex by friends' status) and compared models with the same parameter estimates for males and females with models in which different parameter estimates for males and females were specified. Adding the data from opposite sex DZ (DOS) twins allowed us to examine qualitative sex differences in common environmental influences or, in other words, whether different environmental factors operate in males and females. We compared a model with a freely estimated common environmental correlation in DOS 
twins to a model in which this correlation was fixed to 1 and to a model in which common environment was not correlated to test whether a model in which the common environment is completely shared or not shared at all by males and females may provide a better fit.

With regard to age differences in the frequency distribution of alcohol use, we modeled the regression of age of twins on the thresholds of frequency of drinking and of regular drinking (Prescott 2004).

\section{Results}

\section{Similarity of friends of twins}

We first examined whether MZ twins more often share their friends than DZ twins. Table 1 shows that MZ twins have significantly more often all their friends in common than DZ twins $\left(\chi^{2}(8, n=1526)=136.79, P<.001\right)$. About $20 \%$ of the MZ twins $(20.3 \%$ in the MZM and $18.2 \%$ in the MZF twins) share all their friends. In DZ same-sex twins these percentages were substantially lower (i.e., $4.7 \%$ in DZM and 3.4\% in DZF) and it was particularly low in DZ opposite-sex twin pairs (1.1\%).

Since only few DZ twin pairs shared all their friends, we combined the category "all friends in common" and "different friends, who are similar in alcohol use" into one category, i.e., concordant for alcohol use of friends. For MZM twin pairs, $61 \%$ had friends with similar alcohol use, compared to $49 \%$, of the DZM twins $\left(\chi^{2}(1, n=469)=\right.$ $6.88, P<.01)$. In MZF twins pairs, $58 \%$ had friends with similar alcohol use as compared to $44 \%$ in DZF twin pairs $\left(\chi^{2}(1, n=621)=13.14, P<.001\right)$. The percentage of twins with friends with similar alcohol use, was lowest in the DOS twins (38\%) and this percentage was significantly lower than in the DZM $\left(\chi^{2}(1, n=668)=7.35, P<.01\right)$, but not significantly lower than in DZF twin pairs $\left(\chi^{2}(1, n=700)=2.24, P=.14\right)$ (49 and $44 \%$, respectively).

Table 2 depicts polychoric twin correlations. For both frequency of drinking and regular drinking $\mathrm{MZ}$ correlations were higher than DZ correlations among discordant twins, indicating that genes influence alcohol use in this group. Differences in MZ and DZ correlations in concordant twin pairs were less evident, suggesting smaller genetic effects and increased common environmental influences in this group.

The moderating role of similarities in friends' drinking

Next, we examined whether concordance in friends' drinking moderated heritability estimates for alcohol use. Model fitting results for frequency of drinking and for regular drinking are given in Table 3 . We first tested whether the age regression was equal for males and females in same-sex twins. For both frequency of drinking and regular drinking the model with the sex specific age effect (Table 3, model 1) fitted better to the data than the model without the sex specific age effect (Table 3, model 2). Therefore, sex specific age regressions were retained in all subsequent models.

We continued by examining whether the influence of A, $\mathrm{C}$ and $\mathrm{E}$ for males and females were equal. For both frequency of drinking and regular drinking results showed that the model with different parameters across sex (Table 3, model 3) did not fit the data better than the model with equal parameters across sex (Table 3, model 4). Therefore, all subsequent models were fitted with equal parameter estimates for males and females.

Next we tested for qualitative sex differences using data from same-sex and opposite-sex twins pairs. The common environmental correlation in DOS twins was estimated to be .55 and .59 for frequency of drinking and regular drinking, respectively. We compared this model (Table 3, model 5) to models with the common environmental correlations constrained at 0 (Table 3 , model 6) and 1 (Table 3, model 7). As seen in Table 3, the model with the freely estimated correlation was the best-fitting model for both frequency of drinking and regular drinking.

Finally, we tested whether model parameters for concordant and discordant groups were the same. Both for frequency of drinking and regular drinking, models with different parameters across the two groups (Table 3, model 8) fitted the data better than models with equal parameter estimates across the two groups (Table 3, model 9).

In the final model, age and $\mathrm{A}, \mathrm{C}$ and $\mathrm{E}$ factors loading on frequency of drinking and regular drinking were all

Table 1 Prevalence of similarity in friends and similarity in alcohol use of friends within twin pairs (\%)

\begin{tabular}{|c|c|c|c|c|c|}
\hline & $\begin{array}{l}\text { MZM } \\
n=237\end{array}$ & $\begin{array}{l}\mathrm{DZM} \\
n=232\end{array}$ & $\begin{array}{l}\text { MZF } \\
n=357\end{array}$ & $\begin{array}{l}\text { DZF } \\
n=264\end{array}$ & $\begin{array}{l}\text { DOS } \\
n=436\end{array}$ \\
\hline All friends common & 20.3 & 4.7 & 18.2 & 3.4 & 1.1 \\
\hline Separate friends; similar alcohol use & 40.5 & 44.0 & 40.1 & 40.2 & 36.7 \\
\hline Separate friends; different alcohol use & 39.2 & 51.3 & 41.7 & 56.4 & 62.2 \\
\hline
\end{tabular}

Note: $M Z M$, monozygotic males; $D Z M$, dizygotic males; $M Z F$, monozygotic females; $D Z F$, dizygotic females; $D O S$, dizygotic opposite-sex twins 
Table 2 Number of twin pairs in each group and twin correlations for frequency of drinking and regular drinking as a function of concordance of twins for their friends' alcohol use

Note: $M Z M$, monozygotic males; $D Z M$, dizygotic males; $M Z F$, monozygotic females; $D Z F$, dizygotic females; $D O S$, dizygotic opposite-sex twins

\begin{tabular}{llllll}
\hline & MZM & DZM & MZF & DZF & DOS \\
\hline Frequency of drinking & & & & & \\
Twins concordant friends' alcohol use & $n=144$ & $n=113$ & $n=208$ & $n=115$ & $n=165$ \\
& .75 & .65 & .78 & .68 & .47 \\
Twins discordant friends' alcohol use & $n=93$ & $n=119$ & $n=149$ & $n=149$ & $n=271$ \\
& .77 & .53 & .65 & .43 & .32 \\
Regular drinking & & & & & \\
Twins concordant friends' alcohol use & $n=144$ & $n=113$ & $n=208$ & $n=115$ & $n=165$ \\
& .83 & .79 & .85 & .76 & .48 \\
Twins discordant friends' alcohol use & $n=93$ & $n=119$ & $n=149$ & $n=149$ & $n=271$ \\
& .79 & .55 & .68 & .55 & .45 \\
\hline
\end{tabular}

Table 3 Model fitting results for frequency of drinking and regular drinking

\begin{tabular}{llllll}
\hline vs & $\chi^{2}(d f)$ & $P$ & $\Delta \chi^{2}(d f)$ & $P$
\end{tabular}

Frequency of drinking: same sex twins

Step 1 sex differences in age regression

Age-ACE sex specific age effect ${ }^{\mathrm{a}}$

Age-ACE no sex specific age effect

$\begin{array}{llll} & 50.82(44) & .223 & \\ 1 & 56.62(44) & .096 & 10.38(1) \\ & & & \\ & 50.24(43) & .208 & 1.65(2) \\ & 50.82(44) & .223 & \end{array}$

Step 2 sex differences in a, c, e parameters

Age-ACE sex differences

Age-ACE no sex differences ${ }^{\mathrm{a}}$

Frequency of drinking: all twins

Step 3 qualitative sex differences c parameter

Age-ACE $r_{\mathrm{C}}$ estimated
Age-ACE $r_{\mathrm{C}}$ fixed at 0
Age-ACE $r_{\mathrm{C}}$ fixed at 1

Age-ACE $r_{\mathrm{C}}$ fixed at 1

Step 4 friends differences in a, c, e parameters

Age-ACE differences friends

Age-ACE no differences friends

Regular drinking: same sex twins

Step 1 sex differences in age regression

Age-ACE sex specific age effect

Age-ACE no sex specific age effect

Step 2 sex differences in a, c, e parameters

Age-ACE sex differences

Age-ACE no sex differences

Regular drinking: all twins

Step 3 qualitative sex differences c parameter

$\begin{array}{ll} & 71.80(57) \\ 5 & 78.14(58)\end{array}$

$77.00(58)$

$59.32(57)$

$71.80(57)$

8

$\begin{array}{lll}35.90(35) & .426 \\ 1 & 42.44(36) & .213 \\ & & \\ & 35.30(32) & .315 \\ & 35.90(35) & .426\end{array}$

426

213

$6.00(1)$

.014

315

426

$15.45(1)$

391

090

$17.12(2)$

$$
\begin{aligned}
& \text { Age-ACE } r_{\mathrm{C}} \text { estimated } \\
& \text { Age-ACE } r_{\mathrm{C}} \text { fixed at } 0 \\
& \text { Age-ACE } r_{\mathrm{C}} \text { fixed at } 1
\end{aligned}
$$

Step 4 friends differences in a, c, e parameters

Age-ACE differences friends

Age-ACE no differences friends

$\begin{array}{ll}44.86(45) & .478 \\ 54.64(46) & .179 \\ 50.42(46) & .303 \\ & \\ \mathbf{3 5 . 6 5}(\mathbf{4 3}) & .779 \\ 44.86(45) & .478\end{array}$

.478

303

$13.01(1)$

$<.001$

$7.10(1)$

$11.94(3)$

.008

Note: $A$ additive genetic factor, $C$ common environmental factor, $E$ unique environmental factor. $v s$, versus and indicates to which model the submodel is compared to. Models 1, 2, 3 and 4 are based on analyzes using four groups of same-sex twins and models 5, 6, 7, 8 and 9 are based on analyzes using all five groups of twins (MZM, DZM, MZF, DZF, DOS). $r_{\mathrm{C}}$ common environmental correlation in dizygotic opposite-sex twins. ${ }^{a}$ Model 1 is identical to model 4, both models contain sex specific age effects and no differences in a, $\mathrm{c}$ and e parameters between males and females. Best fitting model in bold 
Table 4 Parameter estimates and percentages explained variance of the best-fitting model for frequency of drinking and regular drinking in twin pairs concordant for friends' alcohol use and discordant for friends' alcohol use

\begin{tabular}{|c|c|c|c|c|c|c|c|c|}
\hline & \multicolumn{2}{|l|}{ Age } & \multicolumn{2}{|l|}{ A } & \multicolumn{2}{|l|}{$\mathrm{C}$} & \multicolumn{2}{|l|}{ E } \\
\hline & Males & Females & Males & Females & Males & Females & Males & Females \\
\hline \multicolumn{9}{|l|}{ Frequency of drinking } \\
\hline Twins concordant friends' alcohol use & $.24(6 \%)$ & $.05(0 \%)$ & $.44(19 \%)$ & $.46(21 \%)$ & $.73(53 \%)$ & $.75(56 \%)$ & $.47(22 \%)$ & $.48(23 \%)$ \\
\hline Twins discordant friends' alcohol use & $.27(7 \%)$ & $.05(0 \%)$ & $.69(47 \%)$ & $.71(50 \%)$ & $.42(18 \%)$ & $.44(19 \%)$ & $.53(28 \%)$ & $.55(30 \%)$ \\
\hline \multicolumn{9}{|l|}{ Regular drinking } \\
\hline Twins concordant friends' alcohol use & $.20(4 \%)$ & $.07(0 \%)$ & $.38(14 \%)$ & $.38(15 \%)$ & $.81(66 \%)$ & $.83(69 \%)$ & $.40(16 \%)$ & $.40(16 \%)$ \\
\hline Twins discordant friends' alcohol use & $.26(7 \%)$ & $.09(1 \%)$ & $.58(33 \%)$ & $.60(36 \%)$ & $.58(34 \%)$ & $.60(36 \%)$ & $.51(26 \%)$ & $.52(27 \%)$ \\
\hline
\end{tabular}

Note: $A$ additive genetic influences, $C$ common environmental influences, $E$ unique environmental influences. The percentage explained variance is depicted between brackets and was obtained by squaring the standardized loadings. Frequency of drinking consisted of eight categories: (1) "I do not drink alcohol", (2) "once a year or less", (3) "a few times a year", (4) "about once a month", (5) "a few times a month", (6) "once a week", (7) "a few times a week", and (8) "daily". Regular drinking was coded dichotomous and was defined as drinking a few times a month and more. Model fit frequency of drinking $\chi^{2}(57)=59.32 ; P=.391$; Model fit regular drinking $\chi^{2}(43)=35.65 ; P=.779$

significant at $P<.001$. The unstandardized parameter estimates for the effects of $\mathrm{A}, \mathrm{C}$ and $\mathrm{E}$ were constrained to be equal for males and females, but the unstandardized age regression coefficient was different for males and females. Parameter estimates were standardized separately for males and females. As a result of the sex difference in age regression, some small differences in standardized parameters between males and females appeared.

Table 4 shows that percentage of the variance explained by each of the 4 factors. In male twins concordant for their friends' alcohol use, the variance in frequency of drinking was explained for $6 \%$ by age, and for $19 \%$ by additive genetic effects, $53 \%$ by common environmental effects and for $22 \%$ by unique environmental effects. For female twins in this group, a similar pattern was seen, with estimations for the effects of age, genes, common environment and unique environment at $0,21,56$, and $23 \%$, respectively. When twins were discordant for the alcohol use of their friends, a different pattern emerged. In male twins, the variance in liability to frequency of alcohol use was explained for $7 \%$ by age and for $47 \%$ by additive genetic effects, while common environment explained $18 \%$ and unique environment $28 \%$ of the variance. For female twins these estimates were 1, 50, 19 and $30 \%$, respectively.

For regular drinking we observed a similar pattern as for frequency of drinking. In male twins concordant for friends' alcohol use, the variance in the liability to regular drinking was explained for $4 \%$ by age, and for $14 \%$ by additive genetic effects, $66 \%$ by common environmental effects and for $16 \%$ by unique environmental effects. We found a similar pattern for female twins, with estimations for the effects of age, genes, common environment and unique environment at $0,15,69$, and $16 \%$, respectively. When twins were discordant for the alcohol use of their friends, the variance in males was explained for $7 \%$ by age and for $33 \%$ by additive genetic effects, while common environment explained $34 \%$ and unique environment $26 \%$ of the variance. For female twins these estimates were 1, 36,36 and $27 \%$, respectively.

Nearly all participants $(92 \%)$ indicated that they had initiated alcohol use. We repeated all analyzes without the $8 \%$ of participants who indicated that they did not drink alcohol, because one could question whether the same genetic and environmental factors explain initiation and continuation of alcohol use. These analyzes revealed similar results as in the analyzes of the complete sample.

With regard to the group of twins who were similar in the behavior of their friends, a further distinction can be made between twins who both had many friends who were regular drinkers and twins who both indicated that half or less of their friends were regular drinkers. Among twins who were similar in the drinking behavior of their friends, $35 \%$ of the MZM, $31 \%$ of the DZM, $24 \%$ of the MZF, $21 \%$ of the DZF and $23 \%$ of the DOS twins indicated that the majority of their friends drink alcohol regularly. For both frequency of drinking and regular drinking, models were not significantly different for the group twins with the majority of their friends being a regular drinker and for twins with half or less of their friends being a regular drinker $\left(\Delta \chi^{2}(3)=3.00, P=.392\right.$ for frequency of drinking and $\Delta \chi^{2}(3)=.67, P=.880$ for regular drinking).

\section{Discussion}

Our study tested to what extent estimates of heritability and common environment for alcohol use in adolescent and young adult twins (16-25 years) are moderated by the similarity of their friends' alcohol use. There is clear evidence for such moderation; being concordant for friends' alcohol use was associated with a decreased heritability and an increased influence of the common environment on 
variation in alcohol use compared to being discordant for the alcohol use of friends. In concordant twins, additive genetic effects explained $14-21 \%$ of the variance in alcohol use, and common environment explained 53-69\% of the variance, depending on the phenotype (frequency or regular drinking). In contrast, in twins discordant for their friends' alcohol use the estimates for the effect of additive genetic factors were higher, ranging from 33 to $50 \%$ while the common environment explained $18-36 \%$ of the variance. The pattern of results was similar for men and women and for frequency of drinking and for regular drinking. Importantly, the contribution of the unique environment to the variance in alcohol use was similar in the groups of concordant and discordant twins. Heteroscedacity, that is differences between the groups in error variances associated with the mean differences in the groups, could have led to differences in the estimates for the proportion of the unique environment and thus lead to group differences in the heritability, without the presence of gene-environment interaction (Boomsma et al. 1999; Eaves 1982). The fact that the contribution of the unique environment was similar in the two groups indicates that the differences in the groups as function of twin similarity in friends' alcohol use are due to gene-environment interaction.

Our results also showed that in adolescence $\mathrm{MZ}$ twins are more likely than DZ twins to have all of their friends in common and that $\mathrm{MZ}$ twins are also more likely than DZ twins to have similarly behaving friends, as was also shown in other studies (Horwitz et al. 2003; Rende et al. 2005; Rose 2002; Walden et al. 2004). These findings can be explained by friendship selection processes. Friendship selection could stem from two sources as it could be socially or genetically mediated. According to the homophily theory people would like to become friends with others who are like themselves (Hogue and Steinberg 1995; Lazarsfeld and Merton 1954). This selection process is socially mediated, and thus MZ twins, who are more similar to each other than DZ twins, are more likely to have similar friends than DZ twins (Rose 2007). Moreover, friendship selection is also likely to have a genetic basis, resulting from the fact that individuals seek out their friends on basis of their genetic makeup (Cleveland et al. 2005; Fowler et al. 2007b, Rose and Dick 2005) and this too would cause $\mathrm{MZ}$ twins to have similar friends more often than DZ twins due to their larger genetic likeness.

Horwitz et al. (2003) argued that previous twins studies might have overestimated the strength of genetic influences and underestimated the strength of common environmental influences, because higher similarities in behavior among MZ compared to DZ twins do not only stem from genetic similarity but also from common environmental influences (i.e., common or behaviorally similar friends). Our results indeed show differences in strength of genetic and common environmental influences in twins with friends who were similar in alcohol use and in twins with friends who were different from each other in alcohol use. However, from the present study it is not clear what factors are related to overor underestimation of results. Several factors might be involved, such as friendship selection which could be environmentally or genetically induced. In fact, our study illustrates that both genes and friends are of importance in adolescent and young adult alcohol use, because the moderating effect of similarity in alcohol use of friends points to a gene by environment interaction. This underscores the importance of incorporating specific environmental factors in behavioral genetic research.

In addition our results seem to indicate that twin similarity of friend's alcohol use and not the extent of alcohol use of friends is important for the heritability of alcohol use. As we did not find differences between twins with the majority of their friends being a regular drinker and twins with half or less of their friends being a regular drinker. This result appears to be inconsistent with results of Dick et al. (2007) that showed that alcohol use among friends moderated estimates of heritability and environmental influences. According to their study additive genetic influences increased with increasing levels of friends' alcohol use. It should be noticed that differences in findings are likely to be explained by the fact that we focused on concordance and discordance in drinking behavior of friends of twins while Dick and colleagues assessed alcohol use of friends of twins by itself.

A few limitations of this study should be noted. It should be stressed that our study does not provide information about the causality in the relation between being concordant for their friends' alcohol use and the similarity in alcohol use within twin pairs. It is not clear whether having behaviorally similar friends causes similarity in alcohol use within twin pairs or whether similarity in alcohol use within twin pairs leads twins to get involved in similar social environments. For this study we constructed a crosssectional dataset from two longitudinal measurement waves. Although analyzes of longitudinal data may provide information regarding the direction of the association between friends' behavior and an individuals' alcohol use, the present information on the alcohol use in friends is limited in the sense that it is not known whether there may have been a change in friends over the time period. We therefore choose to analyze these data cross-sectionally. Previous studies on a similar topic (i.e., social contact within twin pairs, instead of similarity in friends, and similarity in alcohol use) with regard to causality showed mixed results. Two studies using a longitudinal design indicated that social contact within twin pairs leads to similarity in alcohol use in twins (Kaprio et al. 1990; Rose 
et al. 1990), while an other study, not using a longitudinal design, indicated that similarity in alcohol use within twins pairs leads to social contact (Lykken et al. 1990). In addition, we used self-reports of twins to assess frequency of drinking and regular drinking, while drinking of friends was assessed by twin reports on the number of regular drinking friends. It is possible that the twins' own alcohol use may have colored their perception of that of their friends. Future studies may benefit from obtaining selfreport data in both twins and their friends and including them in longitudinal studies.

In conclusion, this study showed that concordance in friends' alcohol use has a moderating effect on the heritability estimates of alcohol use. Genetic factors were more important in the explanation of variation in alcohol use in twins discordant for friends' alcohol use, while common environmental effects were more important in the explanation of variation in alcohol use in concordant twins. These findings illustrate that both genes and friends are relevant in the variation of alcohol use of adolescent and young adult twins.

Open Access This article is distributed under the terms of the Creative Commons Attribution Noncommercial License which permits any noncommercial use, distribution, and reproduction in any medium, provided the original author(s) and source are credited.

\section{References}

Andrews JA, Tildesley E, Hops H, Li F (2002) The influence of peers on young adult substance use. Health Psychol 21:349-357. doi: 10.1037/0278-6133.21.4.349

Ary DV, Tildesley E, Hops H, Andrews J (1993) The influence of parent, sibling, and peer modeling and attitudes on adolescent use of alcohol. Int J Addict 28:853-880

Boomsma DI, De Geus EJ, Van Baal GC, Koopmans JR (1999) A religious upbringing reduces the influence of genetic factors on disinhibition: evidence for interaction between genotype and environment on personality. Twin Res 2:115-125. doi:10.1375/ 136905299320565988

Boomsma DI, Vink JM, Van Beijsterveldt TCEM, De Geus EJC, Beem AL, Mulder EJCM, Derks EM, Riese H, Willemsen GAHM, Bartels M, Van den Berg M, Kupper NHM, Polderman TJC, Posthuma D, Rietveld MJH, Stubbe JH, Knol LI, Stroet T, Van Baal GCM (2002) Netherlands Twin Register: a focus on longitudinal research. Twin Res 5:401-406. doi:10.1375/1369 05202320906174

Boomsma DI, De Geus EJC, Vink JM, Stubbe JH, Distel MA, Hottenga JJ, Posthuma D, Van Beijsterveldt TCEM, Hudziak JJ, Bartels M, Willemsen G (2006) Netherlands Twin Register: from twins to twin families. Twin Res Hum Genet 9:849-857. doi:10.1375/twin.9.6.849

Cleveland HH, Wiebe RP, Rowe DC (2005) Sources of exposure to smoking and drinking friends among adolescents: a behavioralgenetic evaluation. J Genet Psychol 166:153-169

Dick DM, Pagan JL, Viken R, Purcell S, Kaprio J, Pulkkinen L et al (2007) Changing environmental influences on substance use across development. Twin Res Hum Genet 10:315-326. doi: 10.1375/twin.10.2.315
Eaves LJ (1982) The Utility of Twins. In: Anderson VE, Hauser WA, Penry JK, Sing CF (eds) Genetic basis of the epilepsies. Raven Press, New York

Fowler T, Lifford K, Shelton K, Rice F, Thapar A, Neale MC et al (2007a) Exploring the relationship between genetic and environmental influences on initiation and progression of substance use. Addiction (Abingdon, England) 102:413-422. doi:10.1111/ j.1360-0443.2006.01694.x

Fowler T, Shelton K, Lifford K, Rice F, McBride A, Nikolov I et al (2007b) Genetic and environmental influences on the relationship between peer alcohol use and own alcohol use in adolescents. Addiction (Abingdon, England) 102:894-903. doi: 10.1111/j.1360-0443.2007.01824.x

Graham JW, Marks G, Hansen WB (1991) Social influence processes affecting adolescent substance use. J Appl Psychol 76:291-298. doi:10.1037/0021-9010.76.2.291

Heath AC (1987) The analysis of marital interaction in cross-sectional twin data. Acta Genet Med Gemellol 36:41-49

Heath AC, Eaves LJ, Martin NG (1998) Interaction of marital status and genetic risk for symptoms of depression. Twin Res 1:119122. doi: $10.1375 / 136905298320566249$

Hogue A, Steinberg L (1995) Homophily of internalized distress in adolescent peer groups. Dev Psychol 31:897-906. doi:10.1037/ 0012-1649.31.6.897

Hopfer CJ, Crowley TJ, Hewitt JK (2003) Review of twin and adoption studies of adolescent substance use. J Am Acad Child Adolesc Psychiatry 42:710-719. doi:10.1097/01.CHI.00000468 48.56865.54

Horwitz AV, Videon TM, Schmitz MF, Davis D (2003) Rethinking twins and environments: possible social sources for assumed genetic influences in twin research. J Health Soc Behav 44:111129. doi: $10.2307 / 1519802$

Kaprio J, Koskenvuo M, Rose RJ (1990) Change in cohabitation and intrapair similarity of monozygotic (MZ) cotwins for alcohol use, extraversion, and neuroticism. Behav Genet 20:265-276. doi:10.1007/BF01067794

Koopmans JR, Boomsma DI (1996) Familial resemblances in alcohol use: genetic or cultural transmission? J Stud Alcohol 57:19-28

Lazarsfeld PF, Merton RK (1954) Friendship as a social process: a substantive and methodological analysis. In: Berger M, Abel T, Page C (eds) Freedom and control in modern society. Van Nostrand, New York

Lykken DT, McGue M, Bouchard TJ Jr, Tellegen A (1990) Does contact lead to similarity or similarity to contact? Behav Genet 20:547-561. doi:10.1007/BF01065871

Muthén LK, Muthén BO (1998-2006) Mplus user's guide, vol 4. Muthén \& Muthén, Los Angeles

Pagan JL, Rose RJ, Viken RJ, Pulkkinen L, Kaprio J, Dick DM (2006) Genetic and environmental influences on stages of alcohol use across adolescence and into young adulthood. Behav Genet 36:483-497. doi:10.1007/s10519-006-9062-y

Petraitis J, Flay BR, Miller TQ (1995) Reviewing theories of adolescent substance use: organizing pieces in the puzzle. Psychol Bull 117:67-86. doi:10.1037/0033-2909.117.1.67

Poelen EAP, Scholte RH, Engels RCME, Boomsma DI, Willemsen G (2005) Prevalence and trends of alcohol use and misuse among adolescents and young adults in The Netherlands from 1993 to 2000. Drug Alcohol Depend 79:413-421. doi:10.1016/j.drug alcdep.2005.03.020

Poelen EAP, Scholte RHJ, Willemsen G, Boomsma DI, Engels RCME (2007) Drinking by parents, siblings, and friends as predictors of regular alcohol use in adolescents and young adults: a longitudinal twin-family study. Alcohol and Alcoholism (Oxford, Oxfordshire) 42:362-369. doi:10.1093/alcalc/ $\operatorname{agm} 042$ 
Prescott CA (2004) Using the Mplus computer program to estimate models for continuous and categorical data from twins. Behav Genet 34:17-40. doi:10.1023/B:BEGE.0000009474.97649.2f

Rende R, Slomkowski C, Lloyd-Richardson E, Niaura R (2005) Sibling effects on substance use in adolescence: social contagion and genetic relatedness. J Fam Psychol 19:611-618. doi:10.1037/ 0893-3200.19.4.611

Rose RJ (2002) How do adolescents select their friends? A behaviorgenetic perspective. In: Pulkkinen L, Caspi A (eds) Paths to successful development: personality in the life course. Cambridge University Press, Cambridge, UK, pp 106-125

Rose RJ (2007) Peers, parents, and processes of adolescents socialization: a twin-study perspective. In: Engels RCME, Kerr M, Stattin H (eds) Friends, lovers \& groups: key relationships in adolescence. John Wiley \& Sons Ltd., Chichester, UK, pp 105-124

Rose RJ, Dick DM (2005) Gene-environment interplay in adolescent drinking behavior. Alcohol Res Health 28:222-229

Rose RJ, Kaprio J, Williams CJ, Viken R, Obremski K (1990) Social contact and sibling similarity: facts, issues, and red herrings. Behav Genet 20:763-778. doi:10.1007/BF01065919

Urberg KA, Değirmencioğlu SM, Pilgrim C (1997) Close friend and group influence on adolescent cigarette smoking and alcohol use. Dev Psychol 33:834-844. doi:10.1037/0012-1649.33.5.834
Van der Vorst H, Engels RCME, Burk WJ (2007) Can parents teach their children to control to drink responsibly? Parental and friends' influences on the bi-directional associations between drinking at home and drinking outside the home. Health Psychol Rev 1:60

Viken RJ, Kaprio J, Koskenvuo M, Rose RJ (1999) Longitudinal analyzes of the determinants of drinking and of drinking to intoxication in adolescent twins. Behav Genet 29:455-461. doi: 10.1023/A: 1021631122461

Walden B, McGue M, Iacono WG, Burt SA, Elkins I (2004) Identifying shared environmental contributions to early substance use: the respective roles of peers and parents. J Abnorm Psychol 113:440-450. doi:10.1037/0021-843X.113.3.440

Willemsen G, Posthuma D, Boomsma DI (2005) Environmental factors determine where the Dutch live: results from The Netherlands twin register. Twin Res Hum Genet 8:312-317. doi: 10.1375/twin.8.4.312

Wood MD, Read JP, Palfai TP, Stevenson JF (2001) Social influence processes and college student drinking: the mediational role of alcohol outcome expectancies. J Stud Alcohol 62:32-43 